\title{
The Education of Chiropractic Physicians in the United States
}

\author{
Mustafa M. Idris, D.C., F.I.A.C.A.
}

Fountain Valley, California

DOI: http://dx.doi.org/10.5915/22-4-14320

\begin{abstract}
Chiropractic is the science and art which utilizes the inherent recuperative abilities of the body and relationship between the musculoskeletal, vascular and nervous structures and the function of the body principally of the spinal column and the nervous system in the restoration and maintenance of health.

A Doctor of Chiropractic is a primary health care physician concerned with the health needs of the public. As a member of the healing arts, chiropractic physicians give particular attention to the relationship of the structural and neurological aspects of the body in health and disease. In order to accomplish this objective a chiropractor must have an expert knowledge of the body through the study of basic science, clinical science and an Internship in an out-patient clinic. By manipulation of the spinal column and its immediate articulations, chiropractic helps restore and maintain normal nerve function, communication and homeostasis.

The practice and procedures which may be employed by chiropractic physicians are based on academic and clinical training received through an accredited chiropractic college by the Council of Chiropractic Education (CCE). These includes, history taking, physical examination, orthopedic and neurological examination, laboratory diagnosis and radiological interpretation.
\end{abstract}

Key words: Chiropractic, chiropractic physician, nervous system, manipulation, biomechanical analysis, clinical syndromes.

Medical practitioners have many questions about alternate health care. What services do alternative health care providers render? What is their training, educational background, licensing and the scope of practice? How do they inter-relate with main stream medical care? To answer these questions, this article presents an overview of chiropractic medicine - the second largest health care system in the United States. ${ }^{1}$

From Doctors Chiropractic Clinic

Fountain Valley, $C A$

Reprint Requests: Mustafa Idris, M.D.

16200 East Amber Valley Drive

P.O. Box 1166

Whittier, CA 90609-1166
Historical background

While there are three major health care fields in the United States, Allopathic is by far the most predominant, with over 500,000 licensed medical doctors (M.D.s). Chiropractic ranks the second with 40,000 licensed doctors of chiropractic (D.C.s). Doctors of osteopathy (D.O.s) are the third, largely owing to a growth resurgence in the late 70's. ${ }^{2}$

The origins of chiropractic in the United States can be traced to the year $1895,{ }^{3}$ when Daniel David Palmer, a self educated grocer in Davenport, Iowa, applied his reasoning, and discovered a principle which he claimed to be as old as the vertebrates and utilized by the Egyptians, the Incas and many other ancient civilizations. ${ }^{4}$

At the end of nineteenth century, medical care in the United States was far from a flourishing enterprise. Hospitals of the period were poorly equipped to handle illness. Their medical staff were chosen in 
an haphazard way. The medical schools of the period, too, were decidedly inadequate. The medical profession itself was torn by dogmatic struggles between the allopath, the dominant group, and the homeopaths, an insurgent group. The homeopaths vigorously challenged the heavy dosage of drugs in vogue at the time, pointing out that the more modest dosages reduced death rates. It was in this period of medical education, meager hospital care, heroic surgery, and heavy dosages of drugs that chiropractic emerged as an alternative system of healing. ${ }^{5}$ In 1982 the American School of Osteopathy was founded by Dr. Andrew Taylor Still in Kirkville, Missouri. In the course of time five other colleges came into existence in the US. The first chiropractic school was opened in 1898 in Davenport, Iowa.'

On September 18, 1895 D.D. Palmer manipulated a fourth dorsal vertebra of his building janitor, by the name of Harvey Lilard whose hearing was immediately restored after seventeen years of deafness. ${ }^{6}$ This empirical discovery renewed interest in spinal manipulation. The health benefits of spinal manipulation had been known for centuries and it had been practiced in many cultures throughout the world. In fact Hippocrates, the father of medicine, had said "In illness look first to the spine". Andrew Still promoted vertebral manipulation to enhance the functioning of the arterial and nervous system to restore health. Palmer and his followers added specificity and specialization in using the vertebral spinous processes and the transverse processes for short lever manipulation, called chiropractic manipulation ("adjustment"). Many early chiropractors were also medical doctors as are modern ones.' At first all three types of practitioners worked cooperatively together. Gradually rivalry, competition, antagonism and open hostility developed. By the Flexner report of 1910, the nonallopathic schools were relegeted to a lesser status while the allopathic medicine's ascendency began. Chiropractic, osteopathy and other schools of healing survived without government support and with little access to research funds.

During the early part of twentieth century Allopathy, Osteopathy and Homeopathy were absorbed by manistream medicine, having eventually developed a similar scheme of treatment depending mainly on drug therapy and surgery and carried on increasingly in hospitals. By contrast chiropractic maintained its identity by avoiding the use of drugs and surgery, and employing hand treatment which involves a great deal of personal attention to the patient.

\section{What is chiropractic}

Chiropractic was derived from the Greek word "chiro" meaning "hand" and "practikos" meaning "practice", hence the practice by hand, or as it is known at this time, manual medicine. Chiropractic medicine is a primary health care discipline of the scientific healing arts concerned with the pathogenesis, diagnosis, therapeutics and prophylaxis of functional disturbances, pathomechanical states, pain syndromes and neurophysiological effects related to the statics and dynamics of the spinal column and the nervous system, for the restoration and maintenance of health. ${ }^{7,8}$ The chiropractic model of health care is characterized by health oriented, personalized, holistic health care, directed to the cause of the disease, demonstrating expertise in conditions affecting the musculoskeletal system and focusing on biomechanical causes of dysfunction. Chiropractic emphasizes the early diagnosis of functional reversible conditions, intervening by means of manipulation directed at restoring of facilitating the body's natural healing potential, and finally, recognizing the importance of the central nervous system in health.

Chiropractic physicians are skilled in biomechanics and in determining if any spinal column misalignment is interfering with the normal transmission of nervous impulses. Such a misalignment is called a subluxation. Subluxation is defined as an alteration of normal dynamic or anatomic, or physiological relationships of contiguous articulation specially in the spine., ${ }^{9} 10$

\section{Chiropractic educational curriculum}

While chiropractic education has received a great deal of criticism from its opposition, who conveniently forget their own history, the majority of chiropractic colleges have attained a degree of educational excellence by virtually lifting themselves their own bootstraps, without governmental support. The chiropractic college curriculum is essentially similar to those of the medical and osteopathic colleges. Most faculty in chiropractic colleges have a masters, doctoral degree and some have M.D., or D.C. degrees as well. Faculty with Ph.D.s head the departments of anatomy, physiology, biochemistry, pathology, etc. Many of the text books used in medical colleges are also used in chiropractic education. The basic sciences are then applied and integrated into the clinical area program in the last two years of chiropractic education, which comprises the basic core curriculum. The diversity and depth of the curriculum at the chiropractic college assures graduates of being able to sit for national boards and licensure examinations in all 50 states. More importantly, it gives the student the health-care education background necessary to become a primary healthcare provider in the growing health care field. ${ }^{11}$

\section{Admission requirements to chiropractic colleges}

The chiropractic pre-professional requirements are essentially similar to those required by other health- 
care professions offering doctorates. A minimum of two-years of under graduate work, of college or university credit leading to a bachelor's degree including: General chemistry, organic chemistry, biology, anatomy, physics, English, humanities, social science and psychology ${ }^{12,13}$ is reuired before a student matriculates into the five-year chiropractic college curriculum. Many students entering chiropractic college hold graduate or professional degrees from other disciplines and some have higher credentials including Masters and Doctoral degrees. There are some older, change-of-career students, among them nurses, attorneys, dentists and other professionals.

\section{Education and practice}

There 14 accredited chiropractic colleges with about 10,000 students in the United States. These Amrican colleges are accredited by the Council of Chiropractic Education (C.C.E.), which is an agency recognized by the United States Department of Education as the accredited body for chiropractic education it holds membership in the Council of Postsecondary Accreditation (COPA) which facilitates the role of accrediting bodies in promoting and insuring the quality and diversity of American postsecondary education. ${ }^{14,15}$

The completion of the Doctorate degree in Chiropractic medicine consist of 4,700 hours of professional instruction and/or five academic years of the professional training. This includes two years of basic science such as anatomy, neuroanatomy, physiology, neurophysiology, pathology, principles \& practice, public health and community medicine; and two years of clinical science which includes, physical diagnosis, laboratory diagnosis, nutrition, orthopedics, radiology, differential diagnosis; and a year of internship in an out-patient clinic. A candidate for D.C. degree must pass both parts of a national board examination before graduating from chiropractic school. ${ }^{19}$

The license to practice chiropractic is issued only after the candidate passes a three-part (written, oral and practical) state licensing board examination administered by each State Board of Chiropractic Examiners. Unlike the medical profession, chiropractic has little interstate reciprocity in licensing.

Chiropractic scope of practice varies from state to state. In the so called "broad practice states," chiropractic physicians give injections, perform minor surgery and deliver babies. In the "limitedpractice states", the licentiate may be limited to $\mathrm{X}$-ray and spinal manipulation. Therefore, there are a variety of practice laws in all fifty states.

\section{Postgraduate education programs}

The increasing number of graduate doctors of chiropractic wishing to further their education gives evidence to the fact that postgraduate education in most chiropractic colleges has grown rapidly. Increasing number of certification and diplomat advanced education programs are being offered by chiropractic colleges. There are a few chiropractic physicians who are specialized and qualify as diplomates of specialty boards in Radiology, Orthopedic, Nutrition and Sports Medicine. Many chiropractic colleges have begun to co-sponsor interdisciplinary programs with members of the medical faculties of various universities. Interaction with the medical profession and other health care professions has increased enormously. Chiropractic care within hospital settings is now a reality in many states. Discussions about the inclusion of chiropractic colleges in the university settings are occurring in New York, Connecticut, and California. Research on chiropractic principles is becoming an interdisciplinary funcion.

As a primary health care provider, chiropractic physicians serve as a "portal of entry" into the health care system. They are concerned with the restoration and maintenance of health. The safe guarding of health is accomplished largely through what chiropractors call spinal adjustment (manipulation). Chiropractors believe that the neuromusculoskeletal system is a focal point for the cause and alleviation of disease. In treating any condition, the chiropractic physician will focus on prevention and health promotion. The chiropractic approach is always conservative, non-invasive and demands great amount of patient cooperation and responsibility, including appropriate lifestyle and attitude changes.

Like all health care professionals, doctors of chiropractic can treat a large variety of conditions using the natural, conservative approach. ${ }^{16} \mathrm{~A}$ chiropractic practioner is trained to take a complete history and perform a physical examination which includes orthopedic, neurological and biomechanical analysis emphasizing the relationship between structure and function. They can also use laboratory tests and other standard diagnostic tools including X-ray, CT and MRI. Neuromusculoskeletal problems have been shown to respond well to chiropractic care. ${ }^{17-20}$ A study of low back pain and pain control have shown that chiropractic treatment is safe, effective and has minimal side effects. ${ }^{20}$ Scoliosis of the spine can be managed effectively through chiropractic treatment as well as grade I \& II disc protrusions.

When a patient has not responded to chiropractic treatment or a D.C. recognizes the need for prescription drugs or surgical procedures, he/she will make appropriate referral to a medical practitioner. Likewise when spinal manipulation is contraindicated, the chiropractic physician will seek medical/surgical consultation.

As a family practitioner, a doctor of chiropractic 
tries to avoid unnecessary drug $u^{21,22}$ or hospitalization and recommends surgery as a last resort after conservative measures have failed to produce the desired therapeutic outcome. Disc surgery for exmaple should generally not be performed unless a patient has failed to respond to a conservative method, including chiropractic manipulation, traction, bed rest and physical therapy.

Thus chiropractic is one answer to the public health problems of iatrogenic illness, nosocomial infections, and over-utilization of surgical procedures. $^{16}$

\section{Recognition}

Interdisciplinary antagonism has give way in recent years to a more team oriented approach, as physicians of all type work more closely together with more frequent referrals between specialties. The American Medical Association (AMA), which had once declared chiropractic physicians as cultist, changed its principles of Medical Ethics on July 22, 1980 to recognize doctors of chiropractic as limited practitioners and removed obstacles to referral. ${ }^{23}$ Similarly, The American Hospital Association, the American Osteopathic Association, the American Academy of Physical Medicine and Rehabilitation, the North American Academy of Manipulative Medicine, and other groups have all recognized chiropractic medicine.

A famous study from New Zealand in 1979 concluded that chiropractic was remarkably safe and effective and that chiropractors were the only health care pratitioners equipped by education and training to carry out spinal manipulative therapy. ${ }^{24}$ This study, like others, point out the need for more chiropractic research, although this shortcoming has received considerably increased attention in recent years. More research is now underway through major universities.

In 1983 the American Public Health Association, after a lengthy study process, adopted policy No. 8331 , which recognizes chiropractic medicine as safe and effective for neuromusculoskeltal conditions. The Joint Commission on Accreditation of Hospitals (JCAH) evolved from an antichiropractic stance in the 1950 s to a "no policy pro or con" in the lates 70 s, and then to providing in theory for chiropractic hospital privileges in their 1985 standards. ${ }^{25,26}$

Chiropractic physicians are licensed in all 50 states, and are included in a variety of federal, state, and local health programs. ${ }^{27,28}$ Chiropractic care is included in workers' compensation programs and many insurance packages. Union health plans often include chiropractic benefits. Federal funding for chiropractic research and training, and the inclusion of chiropractic in legislationm, is on the increase. ${ }^{29}$ On the recent court ruling of August 27, 1989, judge Susan Getzendanner, United States District Judge for the Northern District of Illinois Eastern Division, found the American Medical Association, The American College of Surgeons, and The American College of Radiology guilty of having conspired to destroy the chiropractic profession in the United States.

\section{Summary}

Chiropractic medicine is a branch of healing arts which provides a portal of entry into the health care delivery system. As a primary physician, a doctor of chiropractic has training in anatomy, pathology, neuroanatomy, physiology, neurophysiology, clinical diagnosis, radiology and spinal biomechanics. Chiropractic physicians recognize many possible causes for disease and subsequently the necessity for many therapeutic approaches as dictated by the cause. However, chiropractic medicine contends that biomechanical aberration of the locomotor system can cause neurologic, physiologic, or pathologic abnormality and that this may have a detrimental effect upon health. It further contends that manipulation and other physical approaches can have beneficial effects upon biomechanical, neurological and other body functions that can modify, correct or prevent disease. Chiropractic treatment emphasizes an approach based upon manipulative and physiological therapeutics, recognizing that its approach is not a panacea and that other therapeutic approaches may be necessary or adjunctively helpful in the treatment of many disease conditions.

\section{References}

1. Stanway A: Alternative medicine: A guide to natural therapies. New York: Penguin, 1979:246.

2. Haldeman S: Modern developments in the principles and practice of chiropractic. New York: Appleton-Century-Crofts, 1980:39.

3. Kelner M, Hall O, Coulter I et al: Chiropractors do they help? A study of their education and practice. Toronto: Fitshenry and Whiteside, 1986:140.

4. Homewood E: The Neurodynamics of Vertebral Subluxation. Third edition. International Standard Book, 1981:47.

5. Reference 3, p. 142.

6. Schafer RC: Chiropractic Health Care. Des Moines, Iowa: Foundation for Chiropractic Education and Research, 1976:37.

7. Reference 2, p. 331.

8. Official definition, Canadian Memorial Chiropractic College, Toronto, Canada, 1976:16.

9. Basic Chiropractic procedural manual, Second edition, Des Moines, Iowa, ACA, pp. IV-54, II-2.

10. Janse J, et al.: Chiropractic Principles and 
Technique. Chicago: National college of Chiropractic, 1947.

11. Sullivan P: Advances in Chiropractic Education. ACA Journal of Chiro 1989; 26:37-39.

12. Los Angeles College of Chiropractic, Catalog 1987-88, Whittier, California.

13. Reference 3, p. 36.

14. Reference 11, p. 37.

15. Baird R: A Chiropractic primer for health record practitioners. ACA Journal of Chiro 1985; 22:32-33.

16. Baird R: The arrogance of the unlimited. The Digest of Chiro 1985; 27:29-34.

17. Reference 2, p. 38.

18. Kane RL, et al: Manipulating the patient a comparision of effectiveness of physician and chiropractic care. Lancet 1974;1:1333-36.

19. Goldstein M: The Research Status of Spinal Manipulative Therapy. NINCDS Monogram, no 15, DEHW Pub. National Institution of Health 76-998. Washington, D.C. p. 155.

20. Mennel J. Back Pain: Diagnosis and treatment using manipulative technique. Boston: Little
Brown and Co., 1960, p. 112.

21. Reference 19 , p. 87.

22. Waterman SA, et al: Do prescriptions adversely affect doctor-patient interactions? AJPH 1981; 71:1358-61.

23. Reese JE. The Evolution of acceptance. Intr Rev of Chiro 1981; 35:7.

24. Chiropractic in New Zealand - Report of the Commission of Inquiry. Wellington, New Zealand, 1979.

25. Joint Commission on Accreditation of Hospitals. Accreditation Manual for Hospitals. Chicago: JCAH, 1985.

26. Richards G. Nonphysician practioners make slow head-way on staff previleges. Hosp 1984; 58:82-86.

27. Reference 6, p. iii.

28. Plan to Ease Medicare Hospital Rules. Medical World News October 1982:77.

29. Burton LE, Smith HH, Nicholas AW: Public Health and Community Medicine, Third edition, Baltimore: Williams and Williams, 1981:600-1. 